Sonja Svoljšak in Urša Kocjan

\title{
Knjiga kot dar: darovalci in darovi $v$ licejski oziroma Cesarsko-kraljevi študijski knjižnici v Ljubljani med 1774 in 1860
}

\section{UVOD}

Obdarovanje s knjigo je staro kot knjiga sama. Podarjanje knjige oziroma zapisane besede izraža naklonjenost, spoštovanje in občudovanje, pa tudi željo po prepoznanju in pripoznanju darovalčeve omikanosti, učenosti in dobrohotnosti. Knjige z željo, da bi delili spomin človeštva, ki v obliki zapisane besede obstane, podarjamo praktično vsi navdušeni bralci in tudi v preteklosti ni bilo bistveno drugače.

Knjige so kot darovi menjale lastnike tudi $\mathrm{v}$ času, ko so bile zaradi dolgotrajnih postopkov izdelave in dragih materialov neprimerno bolj dragocene in redke. Iluminirano Dioskoridovo medicinsko enciklopedijo De Materia medica, ki je bila dokončana okoli leta 512, je kot poročno darilo prejela Anicija Julijana, hči vzhodnorimskega cesarja Flavija Olibrija. ${ }^{1}$ Amienski kodeks, izvrsten in bogato iluminiran prepis latinske Biblije po predlogi iz Kasiodorjevega Vivarija, so v začetku 8. stoletja naredili menihi iz Jarrowa in Wearmoutha in ga leta 716 odnesli na Apeninski polotok, da bi ga podarili papežu Gregorju II. ${ }^{2}$ Splet okoliščin je hotel, da je rokopis pozneje pristal v Medičejski knjižnici v Firencah, ki jo je toskanski nadvojvoda Cosimo I s tem, ko jo je leta 1571 odprl za uporabo tedanjemu izobraženstvu, prav tako na svoj način »podaril« javnosti. Že sto let pred njim je kardinal Bessarion za nastajajočo Marciano, ki je bila na voljo učenjakom oziroma študija željnim Benečanom, prispeval več sto latinskih in grških rokopisov 
ter nekaj inkunabul. ${ }^{3}$ To je le peščica primerov protokolarnega obdarovanja $\mathrm{s}$ knjigo $\mathrm{v}$ srednjem veku ter velikopoteznega humanističnega truda za razširjanje in deljenje učenosti prek darovanja knjig, pa tudi celotnih knjižnih zbirk.

Živahno obdarovanje s knjigami je v srednjem in zgodnjem novem veku zagotovo potekalo tudi pri nas, obstaja pa tudi nekaj dokumentov, ki ga izpričujejo. Znano je na primer, da je kranjski župnik Koloman farni cerkvi svetega Kancijana 2. februarja 1412 podaril čudovito iluminirane Moralije Gregorja Velikega, Misal in Biblijo. ${ }^{4}$ Knjige so si med seboj izmenjevali in podarjali tudi samostanski redovi, ${ }^{5}$ gotovo pa tudi plemiči in drugi posamezniki.

Ena prvih knjižnic na našem ozemlju, ki je v 16. stoletju nastala iz darov ustanoviteljev, pa tudi drugih donatorjev, je bila knjižnica kranjskih deželnih stanov, v katero so posamezne knjige ali zbirke za potrebe izobraževanja širših ljudskih množic oziroma za delovanje protestantske stanovske šole prispevali tedanji pridigarji, plemiči in profesorji, med katerimi so bili tudi Jurij Dalmatin, Adam Bohorič, Primož Trubar, Lenart Budina in Sebastijan Krelj. Njeni začetki segajo v leto 1569, ko je nastajajoči knjižnici kot prvi svojo zbirko zapustil Primož Trubar. $^{6}$

Tudi knjižnica Academie operosorum je v začetku 18. stoletja zrasla s pomočjo darov. Žiga Herberstein, Janez Prešeren in Janez Anton Dolničar so leta 1701 postali njeni prvi darovalci, tako da so zbrali kapital v višini 2000 goldinarjev za plačo knjižničarja in svoje zasebne knjižnice združili ter namenili za javno uporabo. Pozneje se je knjižnični fond še povečal z darovi članov in drugih dobrotnikov, na primer Marka Gerbca, Janeza Jakoba Schillinga, Maksimilijana Raspa, Štefana Florijančiča, Janeza Gašperja Cobenzla in Franca Henrika Raigersfelda. ${ }^{7}$ Tako je bila pretežno iz darov konstituirana prva znanstvena oziroma študijska knjižnica pri nas. V njej so bile zastopane vse vede, zlasti pa teologija, zgodovina, cerkveno in civilno pravo ter medicina, pa tudi leposlovje, glasba, starinoslovje, jezikoslovje, leksikografija, geografija in arhitektura. ${ }^{8}$

V obdobju razsvetljenega absolutizma, ko so pobude in ukrepi za napredek in organizacijo izobraževanja ter razvoj znanosti, s tem pa tudi prepotrebnih študijskih knjižnic, vse bolj prihajali tudi s strani cesarske in deželne oblasti, je bila ustanovljena licejska oziroma Cesarsko-kraljeva študijska knjižnica v Ljubljani. Že v prvem letu obstoja (1774) je v dar prejela tudi prvo zasebno zbirko. Kasneje je število darovalcev in darov še naraščalo in tudi z njimi so nekdanji bibliotekarji-kustosi dopolnjevali vsebine, ki so jih za študij in

3 Labowsky, Bessarion's Library and the Biblioteca Marciana.

4 Adam, "Kranjski antifonar in grb mesta Kranja«, 1-6.

5 Šter, »Srednjeveški koral v kartuziji Žiče».

6 Berčič, O knjigah in knjižničarstvu.

7 Vidmar, »Prva javna znanstvena knjižnica na Slovenskem«, 95-117.

8 Smolik, »Janez Krstnik Prešeren in prva javna znanstvena knjižnica v Ljubljani«, 61-70. 
delo potrebovali študenti in profesorji ljubljanskega liceja, pa tudi širši krog tedanjih kranjskih izobražencev, ki so knjižnico uporabljali.

Pričujoči prispevek predstavlja prvi poskus sistematičnega pregleda darovalcev, ki so svoje zbirke ali posamezne knjige licejski oziroma študijski knjižnici podarili med letoma 1774 in 1860 . Njihovi darovi so lahko popisani kot posebni korpusi ali listine, ${ }^{9}$ zabeleženi v najstarejšem zvezku akcesijskih knjig $^{10}$ ali pa jih navaja Konradova "Zgodovina Cesarsko kraljeve študijske knjižnice v Ljubljani «. ${ }^{11}$ Nekaj posameznih darov je zabeleženih tudi v enem od dodatkov h katalogu licejske knjižnice iz leta $1801 .{ }^{12}$ Rezultati dopolnjujejo dosedanje in tekoče raziskave provenienc historičnih zbirk Narodne in univerzitetne knjižnice. ${ }^{13}$ Poleg posameznikov in ustanov, ki so zabeleženi z imeni, bomo na podlagi pregleda prisotnosti podatkov o nekdanjem lastništvu $\mathrm{v}$ podarjenih knjigah poskušali identificirati tudi darovalce, ki v virih niso navedeni poimensko.

\section{METODOLOGIJA IN VIRI}

Nekateri zgodnejši viri o nastanku licejske knjižnice, s tem pa tudi dokumenti o darovalcih in darovih, so se med selitvami knjižnice in preurejanjem arhiva izgubili ali bili založeni. ${ }^{14}$ Vendar je večina podatkov o obsežnejših donacijah v obdobju od njenih začetkov leta 1774 do leta 1835 zabeležena $\mathrm{v} »$ Zgodovini Cesarsko kraljeve študijske knjižnice v Ljubljani«, ki jo je leta 1909 na podlagi arhivskih virov sestavil Konrad Stefan, ${ }^{15}$ ter v Wildejevem popisu knjižnične zbirke iz leta $1788 .{ }^{16}$ Nekaterih kasnejših darovalcev in darov Stefan sicer ne omenja, so pa navedeni v akcesijskih knjigah, ${ }^{17} \mathrm{ki}$ so začele nastajati leta 1835 pod vodstvom skriptorja, kasneje pa tudi kustosa Mihe Kastelica. Vanje so do leta 1909 sistematično vnašali letni prirast glede na način dotoka gradiva: kupljena dela (glede na vir financiranja), darovi, obvezni izvod in (občasne) zamene. Za obdobje med letoma 1789 in 1835 sicer obstajajo tudi posamezni ohranjeni seznami letnega prirasta oziroma nakupov in donacij, nekaj posameznih darov Žige Zoisa pa nepričakovano

9 Na primer: Verzeichniss der Bucher, welche der gymnasial Prafekt Hr. Baron v. Taufferer in die lyzeal Bibliothek den 1 s April 1791 uberliefert hat, Bucherverzeichniss aus dem Peerischen Verlass, in Verzeichniss der schätzbaren litärerischen Werke, die der Hoch und Wohlgeborne freyherr Sigismund von Zois der diesortigen Lyceal-Bibliothek in den Jahren 1808 und 1815 als ein Geschenk verehret hat.

10 Accessions-Protokolle der Studienbibliothek in Laibach.

11 Stefan, Zgodovina C. kr. študijske knjižnice v Ljubljani.

12 Bibliothecae Caes. Reg. Lycei Labac. Catalogi Supplementum I.

13 Svoljšak in Kocjan, Provenience starih tiskov Narodne in univerzitetne knjižnice.

14 Kodrič-Dačić, »Konrad Stefan in njegova zgodovina Cesarsko kraljeve Študijske knjižnice v Ljubljani«, 70-73.

15 Stefan, Zgodovina C. kr. študijske knjižnice v Ljubljani.

16 Verzeichniss der Laybacher akademischen Büchersammlung kraft des gemachten Inventariums den 4ten May 1788.

17 Accessions-Protokolle der Studienbibliothek in Laibach. 
navaja tudi prvi dodatek k prvemu katalogu licejske knjižnice iz leta $1801 .^{18}$ V najzgodnejši akcesijski knjigi, ki obsega obdobje od leta 1835 do leta 1860, so darovalci navedeni poimensko ali pa je zapisan samo seznam darovanih naslovov za posamezno leto. Izziva za rekonstrukcijo podatkov o darovalcih pa ne predstavljajo samo razlike med navedbami v Stefanovem pregledu in seznami domnevno anonimnih darov v akcesijski knjigi. Zaradi neurejenosti primarnih seznamov donacij in drugih s tem povezanih dokumentov prihaja tudi do odstopanj med navedbami leta dejanskega prevzema posameznega daru v Stefanovem pregledu in letom vpisa v akcesijsko knjigo, saj je slednje praviloma nekoliko kasnejše od leta prevzema. Kronološki seznam darovalcev in darov, ki bo predstavljen v naslednjem poglavju, bo v osnovi temeljil na letu izražene namere darovalca (oporoka, volilo), kadar je to razvidno iz katerega koli od zgoraj navedenih virov, v primeru odstopanja pri vpisu v akcesijsko knjigo pa bo v oklepaju dodano še pojasnilo o letu vpisa. Kadar leto prevzema ne bo znano, bo navedeno samo leto vpisa $\mathrm{v}$ akcesijsko knjigo $\mathrm{z}$ ustreznim pojasnilom. Pri vsakem darovalcu bodo navedeni osnovni biografski podatki, število naslovov in zvezkov, ki jih je daroval, kadar so ti podatki znani oziroma jih je mogoče ugotoviti na podlagi primarnih ali sekundarnih virov, ter okvirna vsebina darov. V zadnjem poglavju bo predstavljen še pregled števila in deleža darov glede na skupni obseg knjižnične zbirke v letu 1860, pregled vsebin, ki so jih za potrebe uporabnikov licejske knjižnice prispevali darovalci, ter analiza pomena darov za razvoj licejske knjižnice.

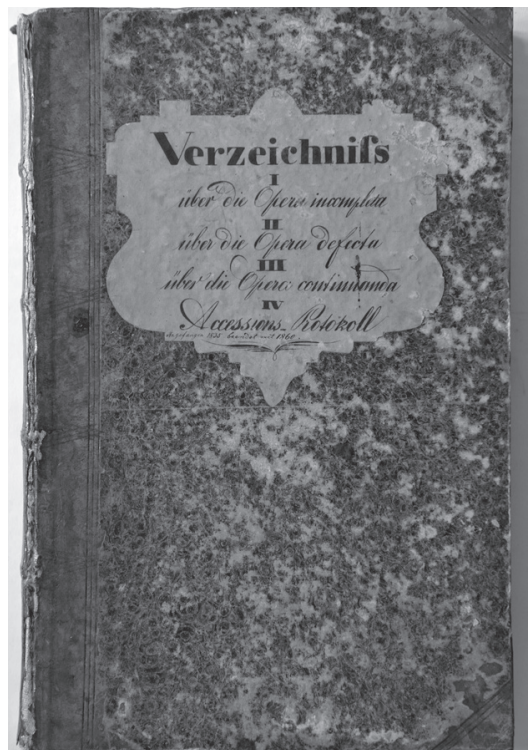

Slika 1: Srednja platnica najzgodnejše akcesijske knjige

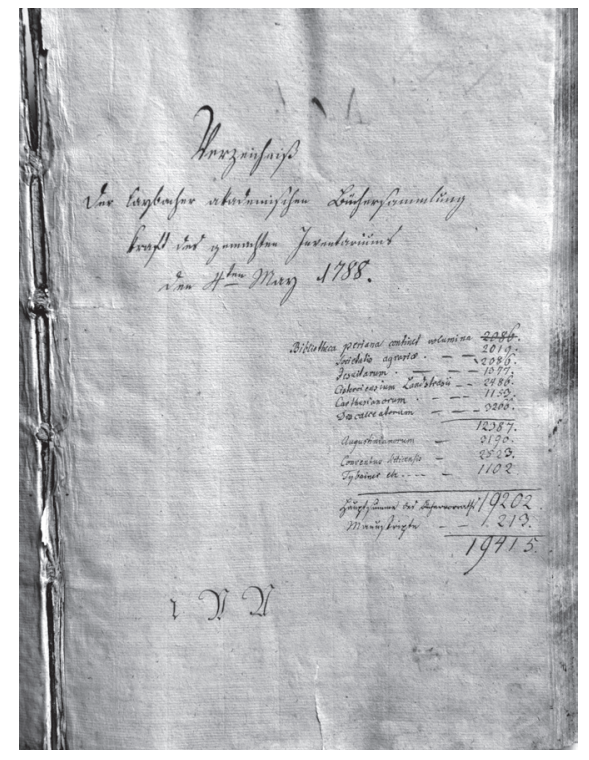

Slika 2: Prvi list Wildejevega popisa knjižnične zbirke iz leta 1788

18 Vir: Bibliothecae Caes. Reg. Lycei Labac. Catalogi Supplementum I. 


\section{KRONOLOŠKI PREGLED DAROVALCEV IN NJIHOVIH DAROV}

\section{4 (prevzem 1774)}

Svetnik deželnega glavarstva Mihael Amadej Janez Raigersfeld (1744$1783)^{19}$ je knjižnici podaril družinsko zbirko knjig. Poseben seznam darov ni ohranjen, Wildejev popis iz leta $1788^{20}$ pa to donacijo - glede na do zdaj identificirane knjige, ki so bile nekoč v lasti rodbine Rakovec, ni mogla biti prav obsežna - najverjetneje navaja kar v okviru seznama 962 knjig, obsegajočega 637 naslovov iz knjižnice pogorelega jezuitskega kolegija ter drugih knjig, ki so jih istega leta postopoma vračali študenti in profesorji. ${ }^{21}$

1774 (prevzem 1806, vrnjeno 1839)

Grof Jošt Vajkard Barbo von Waxenstein (1702-1775) je v svoji oporoki z 8. julija $1774 \mathrm{v}$ varstvo in uporabo licejski knjižnici odstopil 704 naslove. 6. septembra 1806 je Wilde Barbovo knjižnico tudi prevzel. Knjižnica je bila sicer leta 1839 iz različnih razlogov, predvsem pa zaradi prostorske stiske in nespoštovanja pogodbenih obveznosti s strani rodbine Barbo, izločena iz zbirke ter vrnjena rodbini. 25. januarja 1839 jo je prevzel Otto Barbo. Vse dokler zbirka ni bila vrnjena, je bila hranjena ločeno in nikoli ni bila v celoti popisana. ${ }^{22}$

\section{6 (prevzem 1778)}

Ljubljanski generalni vikar Karel Peer (1697-1776) ${ }^{23}$ je knjižnici podaril svojo, pretežno teološko, cerkvenopravno in zgodovinsko zbirko, ki obsega 1022 naslovov oziroma 2019 zvezkov. $^{24}$

\section{2 (prevzem 1792)}

Baron Inocenc Taufferer (1722-1794), ${ }^{25}$ gimnazijski prefekt in bibliotekarkustos licejske knjižnice do leta 1792, je ob upokojitvi knjižnici podaril 43 naslovov v 85 zvezkih pretežno teološke vsebine. ${ }^{26}$ Profesor poetike in retorike na liceju Janez Jakob Knauer (1740-1819) ${ }^{27}$ je knjižnici podaril 50 del v 57 zvezkih. ${ }^{28}$ Prevladujejo leposlovne vsebine, na čelu $\mathrm{z}$ antično književnostjo.

19 Rudolf, »Raigersfeld rodbina«.

20 Verzeichniss der Laybacher akademischen Büchersammlung kraft des gemachten Inventariums den 4 ten May 1788.

21 Specification deren Büchern welche zum Theill in dem gewesten Collegio zu Laybach in einen Kasten verwahret gewesen, und zum Theill durch Studentes nach und nach zusammen getragen worden.

22 Stefan, Zgodovina C. kr. študijske knjižnice v Ljubljani, 20 in 49, in Zbirka posameznih popisov donacij.

23 Kidrič, »Peer, Karel, plemeniti«.

24 Stefan, Zgodovina C. kr. študijske knjižnice v Ljubljani, 7, in Bucherverzeichniss aus dem Peerischen Verlass.

25 Gspan, »Taufferer, Inocenc, plemeniti«.

26 Verzeichniss der Bucher, welche der gymnasial Prafekt Hr. Baron v. Taufferer in die lyzeal Bibliothek den 1 A April 1791 uberliefert hat.

27 Glonar, »Knauer, Janez Jakob«.

28 Stefan, Zgodovina C. kr. študijske knjižnice v Ljubljani, 20 in Zbirka posameznih popisov donacij 1774-1834. 


\section{4}

3. februarja 1794 je ljubljanski zdravnik Jakob Pfandl (ca. 1760-1831) ${ }^{29}$ knjižnici podaril 21 medicinskih oziroma naravoslovnih del v 19 zvezkih. ${ }^{30}$

\section{7}

4. oktobra 1797 je stanovsko zastopstvo odposlancev knjižnici podarilo knjige, ki so pripadale flachenfeldskemu kanonikatu. Dar je obsegal 105 naslovov v 154 zvezkih. ${ }^{31}$ Prevladujeta cerkveno pravo in teologija.

(Po) 1801

Baron, industrialec, naravoslovec in mecen Žiga Zois $(1747-1819)^{32}$ je licejski knjižnici podaril 26 del v 216 zvezkih. Prevladujejo uporabne vede (gospodartvo, kmetijstvo, tehnika) in naravoslovje (botanika, fizika, kemija). ${ }^{33}$

1809

Franc Ksaver Wilde (1752-1828), ${ }^{34}$ profesor na liceju in bibliotekar-kustos v licejski knjižnici od leta 1783 do leta 1809, je ob francoski okupaciji svojo službo bibliotekarja deželni vladi vrnil, pred odhodom na Dunaj naslednje leto pa je knjižnici zapustil še 144 naslovov v 173 zvezkih iz svoje zbirke. ${ }^{35}$ Prevladujejo zgodovina, pravo in različna referenčna literatura.

1811

Maja 1811 je Hieronymus Agapito (1783-1844), ${ }^{36}$ profesor retorike in zgodovine ter bibliotekar-kustos v licejski knjižnici med letoma 1810 in 1812, podaril 28 naslovovv 37 zvezkih. ${ }^{37}$ Prevladuje italijanska književnost.

1808 in 1815

Žiga Zois je v letu 1808 in 1815 licejski knjižnici podaril 76 naslovov v 458 zvezkih $^{38}$ s področja zgodovine, klasične književnosti, naravoslovja in jezikoslovja. ${ }^{39}$

29 Pintar, »Pfandl, Jakob«.

30 Popis je dodan na koncu: Verzeichniss der Laybacher akademischen Büchersammlung kraft des gemachten Inventariums den 4ten May 1788. Stefan navaja 20 del v 19 zvezkih, izpuščen je en privezek (Stefan, Zgodovina C. kr. študijske knjižnice v Ljubljani, 24).

31 Stefan, Zgodovina C. kr. študijske knjižnice v Ljubljani, 27, in Zbirka posameznih popisov donacij 1774-1834.

32 Valenčič et al., "Zois plemeniti Edelstein, Žiga«.

33 Bibliothecae Caes. Reg. Lycei Labac. Catalogi Supplementum I.

34 Pivec-Stelè, »Wilde, Franz Xaver«.

35 Stefan, Zgodovina C. kr. študijske knjižnice v Ljubljani, 34, in Zbirka posameznih popisov donacij 1774-1834.

36 Kranjc, »Agapito, Girolamo«.

37 Stefan, Zgodovina C. kr. študijske knjižnice v Ljubljani, 35, in Zbirka posameznih popisov donacij 1774-1834.

38 Do velikega odstopanja med številom naslovov in zvezkov pri Zoisovi donaciji prihaja zato, ker posamezna dela obsegajo tudi 20, 30, 40 ali več zvezkov.

39 Verzeichniss der schätzbaren litärerischen Werke, die der Hoch und Wohlgeborne freyherr Sigismund von Zois der diesortigen Lyceal-Bibliothek in den Jahren 1808 und 1815 als ein Geschenk verehret hat. 


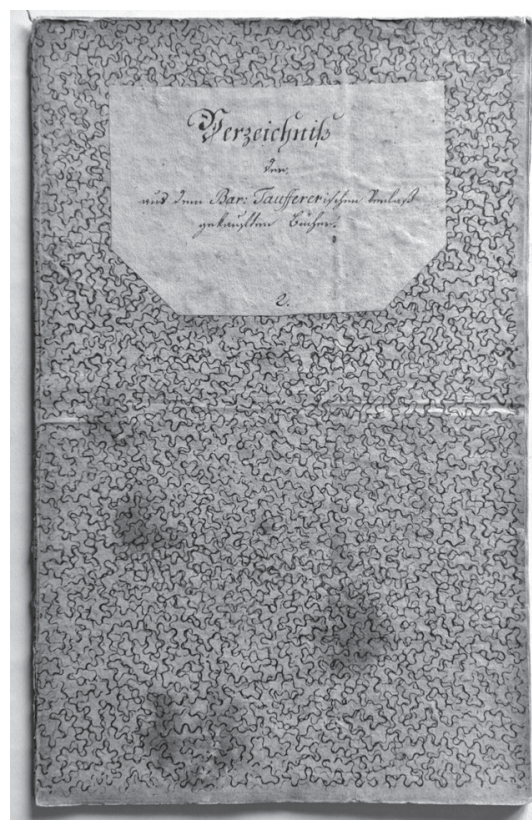

Slika 3: Seznam Tauffererjevih darov

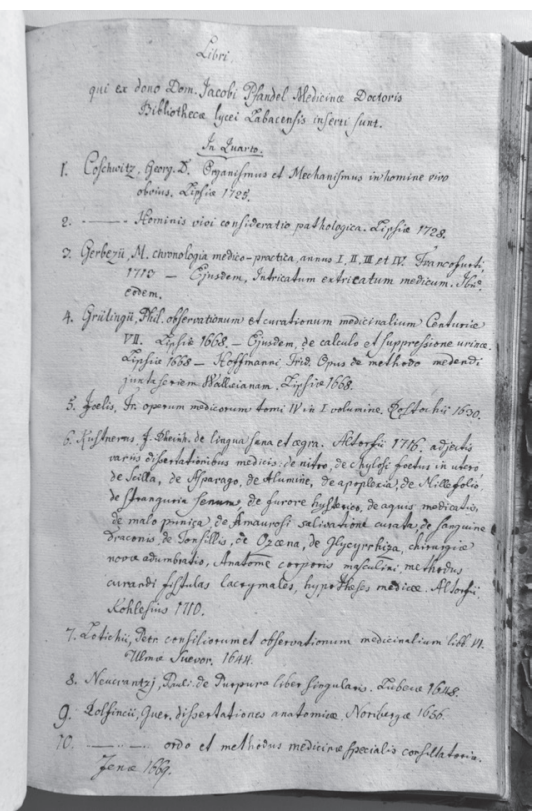

Slika 5: Seznam Pfandlovih darov

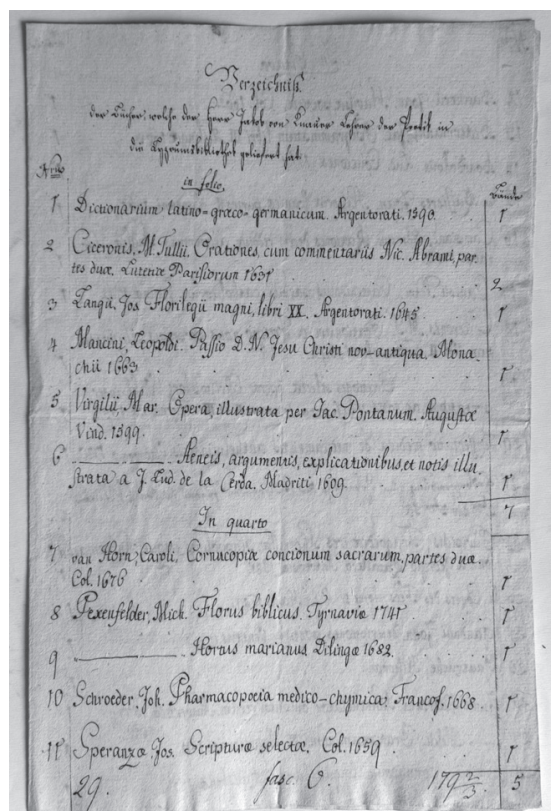

Slika 4: Seznam Knauerjevih darov

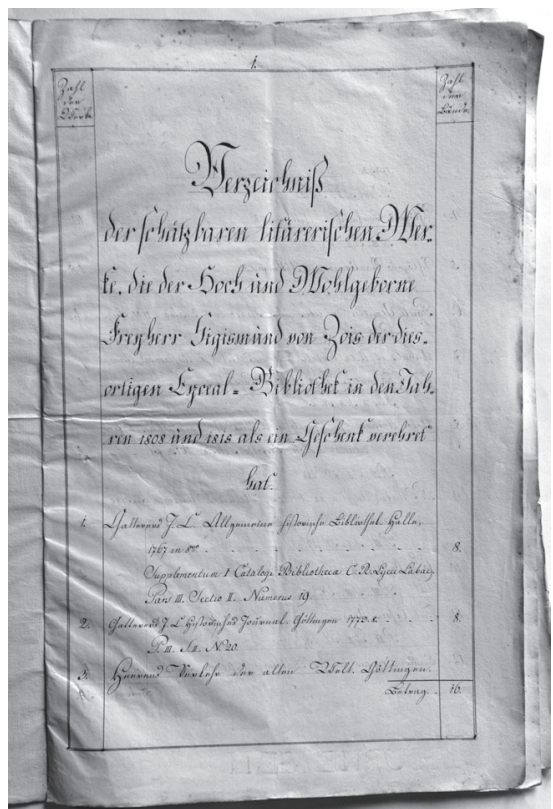

Slika 6: Seznam Zoisovih darov iz leta 1808 in 1815 
23. februarja 1820 je grof Alfonz Porzia (u. 1876) knjižnici podaril delo Omaggio delle Provincie Venete alla Maesta di Carolina Augusta iz leta 1818. Istega leta je knjižnica prejela še nekaj cesarskih darov, med drugim tudi dela: Il costume antico e moderno (Milano, 1817, 21 zvezkov), Storia della scultura dal suo risorgimento (Venezia, 1813, 3 zvezki), Pinacoteca del palazzo reale di Milano (Milano, 1812, 3 zvezki), Chiese principali d'Europa (Milano, 1824), La fabbriche più cospicue di Venezia misurate (Venezia, 1815 ) in Plantarum Brasiliae icones (Vindobonae, 1827, 2 zvezka). ${ }^{40}$

\section{$1833 / 34$}

Ohranjena je samostojna listina, ki navaja 6 darov s področja medicine, naravoslovja, bibliografije in antične književnosti. Darovalci so bili: zdravnika Octav Perman von Vest (1 naslov) in Ignaz Hoffman (1 naslov), lastniki knjigarne Damian und Sorge iz Graza (1 naslov) in bibliotekarskriptor v knjižnici dunajske univerze Johann Krausler (3 naslovi). ${ }^{41}$

1836 (leto vpisa v akcesijsko knjigo)

Botanik in profesor Franc Hladnik (1773-1844) $)^{42}$ je knjižnici podaril 147 naslovov, pretežno naravoslovne vsebine (botanika). ${ }^{43}$

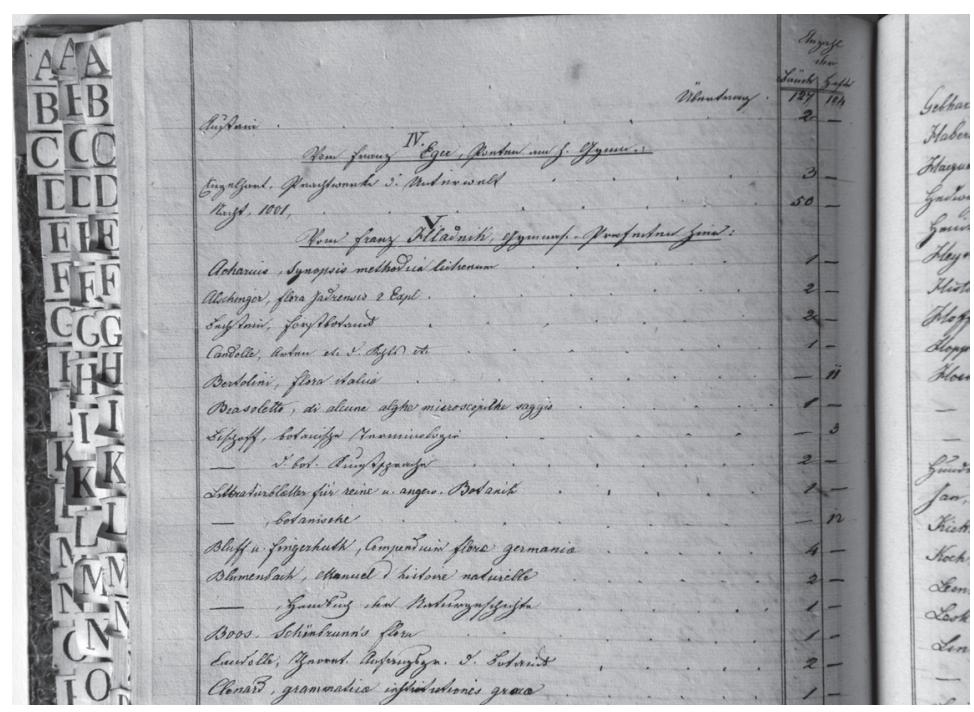

Slika 7: Vpis Hladnikove donacije v akcesijski knjigi za leto 1836

40 Stefan, Zgodovina C. kr. študijske knjižnice v Ljubljani, 37, in Zbirka posameznih popisov donacij. Poseben seznam darov grofa Porzie ni ohranjen.

41 Zbirka posameznih popisov donacij 1774-1834.

42 Pintar, »Hladnik, Franc de Paula«.

43 Accessions-Protokolle der Studienbibliothek in Laibach in Stefan, Zgodovina C. kr. študijske knjižnice v Ljubljani, 27. 
1837 (leto vpisa v akcesijsko knjigo)

Franc Hladnik je knjižnici podaril še 8 naslovov. ${ }^{44}$

1840 (leto vpisa v akcesijsko knjigo)

Kranjska kmetijska družba je knjižnici podarila 6 letnikov svojih analov. (Franc Jožef?) Hohenwart (1771-1844) je podaril 1 knjigo. Franc Hladnik je prispeval 4 knjige s področja naravoslovja in botanike. František Ladislav Čelakovský (1799-1852), češki pesnik, prevajalec in narodni buditelj iz Prage, je podaril 6 tiskov v češkem jeziku. Zdravnik in veterinar Anton Hayne (1786-1853) je knjižnici poklonil 3 svoja dela s področja veterine in medicine, licejski rektorat pa 31 inavguralnih disertacij. ${ }^{45}$

1841 (leto vpisa v akcesijsko knjigo)

Knjižnica je prejela 4 knjige, dar profesorja Hladnika. ${ }^{46}$

1842 (leto vpisa v akcesijsko knjigo)

Knjižnici je podaril 2 knjigi profesorj Hladnika, 4 knjige agronom in profesor Franc Ksaver Hlubek (1802-1880) in 1 knjigo veterinar, publicist in politik ter profesor Janeza Bleiweisa (1808-1881). ${ }^{47}$

1843 (popisano v akcesijsko knjigo: 1846)

Kranjski deželni muzej je knjižnici podaril 365 naslovov (675 zvezkov, 117 snopičev in 71 listov). ${ }^{48}$ Prevladuje zgodovinopisje.

1844 (leto vpisa v akcesijsko knjigo)

Knjižnici je podaril 2 naslova profesor Hladnik ${ }^{49}$ ter 1 izvod inavguralne disertacije s področja medicine licejski rektorat.

1945 (leto vpisa v akcesijsko knjigo)

Knjižnica je prejela še 5 posmrtnih darov od profesorja Hladnika. ${ }^{50}$

1846 (leto vpisa v akcesijsko knjigo)

Anonimni darovalec je knjižnici poklonil delo Acta et decreta synodi cleri romano-catholici provinciae Ultrajectensis s šestimi privezki sorodne vsebine. Knjiga ne izkazuje znakov nekdanjega lastništva.

\footnotetext{
44 Accessions-Protokolle der Studienbibliothek in Laibach.

45 Prav tam.

46 Prav tam.

47 Accessions-Protokolle der Studienbibliothek in Laibach.

48 Stefan, Zgodovina C. kr. študijske knjižnice v Ljubljani, 50, in Accessions-Protokolle der Studienbibliothek in Laibach.

49 Accessions-Protokolle der Studienbibliothek in Laibach.

50 Accessions-Protokolle der Studienbibliothek in Laibach..
} 
1847 (leto vpisa v akcesijsko knjigo)

Navedenih je 41 del anonimnih darovalcev. Glede na to, da eno od njih (Budikova Über das gekrönte Trauerspiel König Ottokar des Nikoalus Vernulaeus, 1845) vsebuje posvetilo avtorja (Bibliothecae caes. reg. Labacensis D. D. Auctor) in da gre večinoma za slovansko jezikoslovje in književnost, je mogoče predvidevati, da gre za dar literarnega zgodovinarja in bibliotekarja-kustosa na celovškem liceju Petra Alcantare Budika (1792-1858). ${ }^{51}$

1848 (leto vpisa v akcesijsko knjigo)

Jezikoslovec in dvorni knjižnični uradnik Fran Miklošič (1813-1891) je knjižnici podaril 31 naslovov, predvsem slavike, v 34 zvezkih. ${ }^{52}$

1849 (vpis v akcesijsko knjigo: 1851)

Dvorni svetnik in grof Karl Welsperg (1779-1873) je knjižnici podaril 320 del v 324 zvezkih, večinoma pravne vsebine. ${ }^{53}$

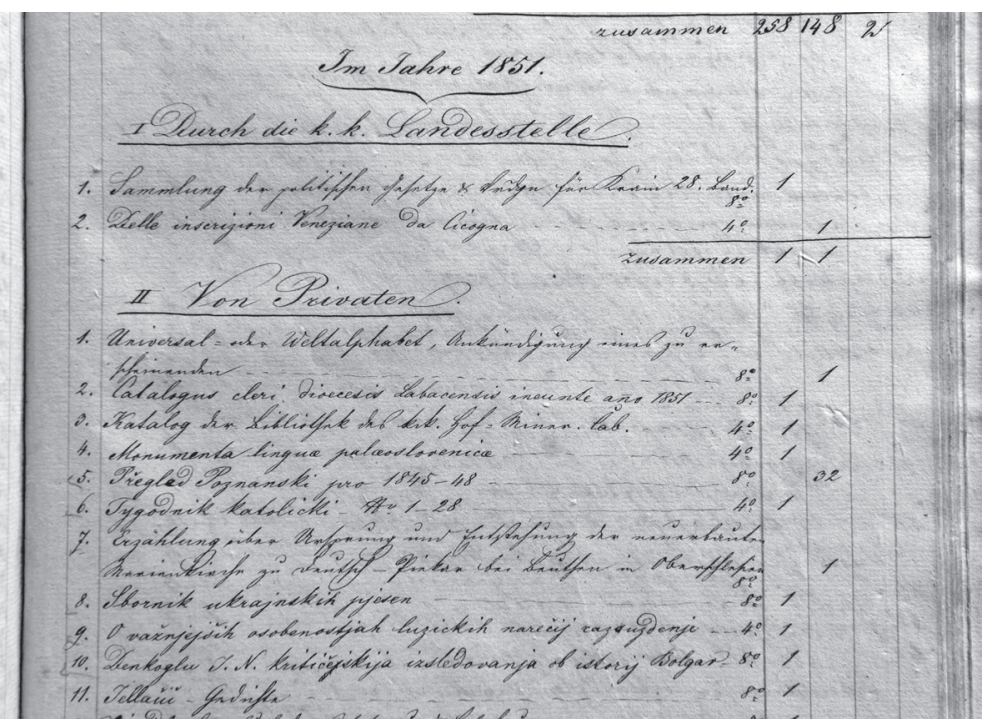

Slika 8: Seznam Welspergovih darov v akcesijski knjigi za leto 1851

1850 (leto vpisa v akcesijsko knjigo)

Knjižnica je prejela 7 darov. Darovalci niso zabeleženi poimensko, je pa v Miklošičevi Formenlehre der altslovenischen Sprache zapisano avtorjevo

51 Accessions-Protokolle der Studienbibliothek in Laibach.

52 Konrad kot leto prejema daru sicer navaja leto 1949 (Stefan, Zgodovina C. kr. študijske knjižnice $v$ Ljubljani, 52), vendar pa so knjige v akcesijskih protokolih zabeležene že leta 1848; AccessionsProtokolle der Studienbibliothek in Laibach.

53 Stefan, Zgodovina C. kr. študijske knjižnice v Ljubljani, 68, in Accessions-Protokolle der Studienbibliothek in Laibach. 
posvetilo Mihi Kastelicu (1796-1868), ki je bil bibliotekar-kustos v licejski knjižnici med letoma 1850 in 1865 . Morda gre za Kasteličev dar. ${ }^{54}$

1852 (leto vpisa v akcesijsko knjigo)

Knjižnica je prejela 8 darov. Razen koledarčka za leto 1853, ki vsebuje lastniški vpis učitelja, šolnika in pesnika Jožefa Levičnika (1806-1909), ne prinašajo podatkov o darovalcih. ${ }^{55}$

1853 (leto vpisa v akcesijsko knjigo)

Cesarska geološka družba z Dunaja je poklonila 4 letnike svojih analov.

1854 (leto vpisa v akcesijsko knjigo)

Josef Pavol Šafárik (1761-1831), slovaški jezikoslovec, pesnik, slavist, literarni zgodovinar, zgodovinar, etnograf in bibliotekar, je knjižnici podaril 64 naslovov. $^{56} 15$. februarja 1854 je gimnazija (nekdanji licej) študijski knjižnici odstopila 9 del v 10 zvezkih. ${ }^{57}$

1859 (leto vpisa v akcesijsko knjigo)

V letu 1859 je knjižnica prejela dar sina Franca Jožefa Hanibala Hohenwarta (1771-1844) grofa Andreja Hohenwarta v obsegu 66 del v 85 zvezkih, pretežno pravne zgodovinske in naravoslovno-tehnične vsebine. $\mathrm{V}$ istem letu so knjige darovali še zagrebški pravnik Leopold Krainz (12 knjig), dunajski profesor Alois Egger (2 naslova v 9 zvezkih), literarni zgodovinar in slavist Anton Janežič (1828-1869) (1 knjigo) ter ljubljanski knjigotržec Jurij Lercher (5 knjigotrških katalogov) ${ }^{58}$

1860 (leto vpisa v akcesijsko knjigo)

Profesor Franz Hrovath (1823-?) $)^{59}$ je knjižnici podaril 3 naslove, bibliotekar skriptor Jurij Kosmač (1799-1872) 13 naslovov, mestni svetnik Josef Köstl $(1817-?)^{60}$ pa 11 naslovov. Josef Pavol Šafárik, Johann Lego, Emil Čakra, Anton Janežič in Gaetano Sorgato iz padovskega bogoslovnega semenišča so knjižnici podarili vsak po 1 knjigo. Jožef Zalokar, jubilejni profesor, je knjižnici podaril 33 naslovov, Miha Kastelic pa 153 naslovov. ${ }^{61}$

\footnotetext{
54 Accessions-Protokolle der Studienbibliothek in Laibach.

55 Prav tam.

56 Prav tam.

57 Ko je bil licej leta 1850 ukinjen, se je knjižnica ločila od na novo organizirane gimnazije, ki si je uredila svojo lastno knjižnico. Stefan, Zgodovina C. kr. študijske knjižnice v Ljubljani, 53-54.

58 Stefan, Zgodovina C. kr. študijske knjižnice v Ljubljani, 56, in Accessions-Protokolle der Studienbibliothek in Laibach.

59 "Aufnahms-Bogen auf Jahre 1816."

60 Stariha, "Pri tem je odpel hlače in...'", 31.

61 Accessions-Protokolle der Studienbibliothek in Laibach.
} 


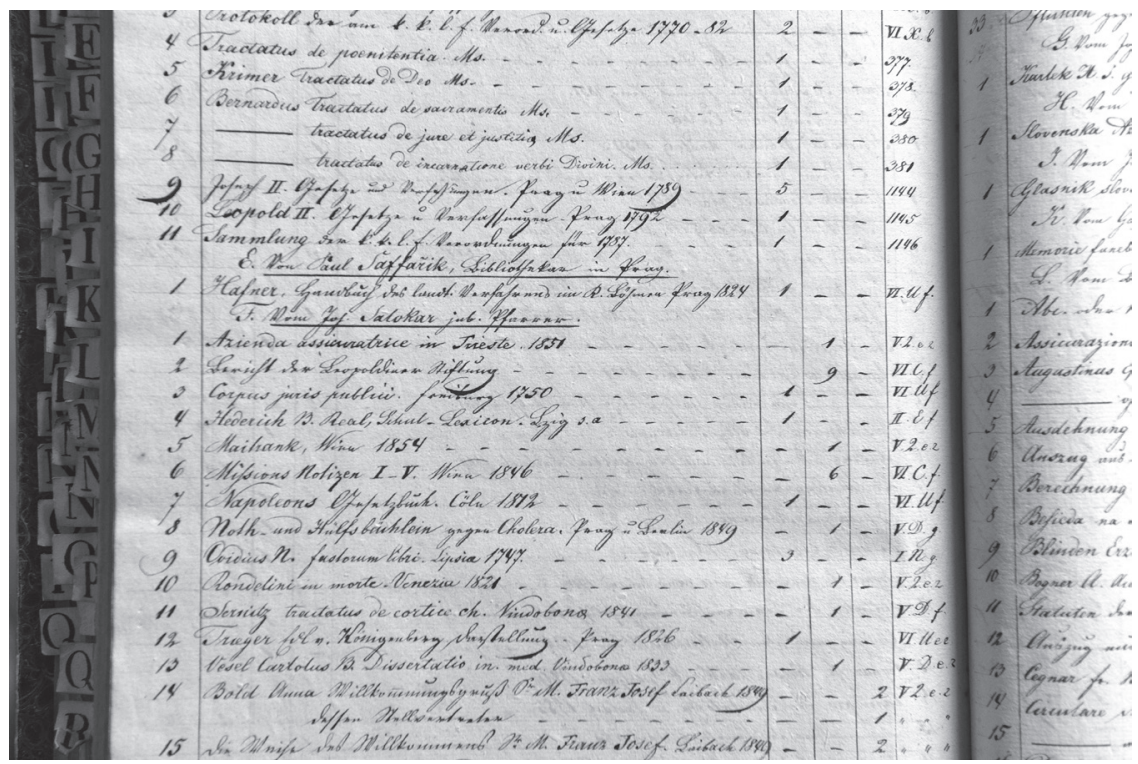

Slika 9: Del seznama darovalcev vakcesijski knjigi za leto 1860

\section{DELEŽ, VSEBINA IN POMEN DAROV V LICEJSKI KNJIŽNICI}

Konec leta 1860 je zbirka študijske oziroma nekdanje licejske knjižnice obsegala 23.858 naslovov in 33.585 zvezkov, poleg tega pa še 273 snopičev in 843 posameznih listov. ${ }^{62}$ Gre za prečiščene podatke brez izločenih dvojnic in nepopisanih knjig. Darovi posameznikov in ustanov do tega leta obsegajo 3077 naslovov, ${ }^{63}$ kar predstavlja približno $13 \%$ celotnega fonda. Vendar je pri oceni obsega in pomena darov treba upoštevati dejstvo, da je licejska knjižnica v prvih desetletjih po ustanovitvi gradivo pridobivala tudi iz naslova političnoupravnih reform ter prek posameznih drugih pogodbenih aktov. Upoštevajoč število naslovov, ki jih je prejela na tak način (torej ne $\mathrm{z}$ neposrednimi nakupi iz rednih in občasnih nabavnih sredstev), je odstotek podarjenih knjig občutno višji. Če od skupnega števila naslovov odštejemo velike zbirke, kot so ostanki knjižnice ljubljanskega jezuitskega kolegija, knjižnico kartuzije Bistra, knjižnici kostanjeviškega in stiškega cistercijanskega samostana, gornjegrajsko knjižnico, knjižnico samostana devinskih servitov, knjižnici ljubljanskih samostanov bosonogih in obutih avguštincev ter knjižnico kranjske kmetijske družbe, ki so bile pridobljene iz naslova cesarskih upravnih reform in z drugimi pogodbami, ter upoštevamo še podatek, da je bilo do leta 1860 iz zbirke

62 Stefan, Zgodovina C. kr. študijske knjižnice v Ljubljani, 54.

63 Brez Barbove knjižnice in Raigersfeldove donacije, katere obsega ni mogoče z gotovostjo oceniti. 
izločenih več kot 1000 dvojnic, nekaj gradiva pa sploh ni bilo popisanega, odstotek darov naraste na nekoliko več kot 40 \% celotnega knjižničnega fonda, kar vsekakor ni zanemarljivo. Večino gradiva sicer predstavljajo redni nakupi, obvezni izvod (od leta 1807, sistematično beleženje v akcesijsko knjigo šele od leta 1835 dalje) ter nekaj večjih namenskih nakupov, kot so knjižnice Jerneja Kopitarja, Matije Čopa in Žige Zoisa. ${ }^{64}$

Med 36 darovalci, ki so svoje zbirke ali posamezne knjige zapustili licejski oziroma študijski knjižnici, je 7 ustanov in 29 posameznikov. Deset posameznikov lahko neposredno povežemo zlicejsko knjižnico oziroma licejem in s kasnejšim učnim zavodom (profesorji, študenti in bibliotekarji). Drugi so opravljali visoke cerkvene, mestne ali deželne funkcije, ali pa so pripadali tedanjemu mestnemu oziroma deželnemu izobraženstvu (profesorji, pravniki, zdravniki). Nekateri so delovali na pomembnih visokošolskih ustanovah ali pa so zasedali visoke položaje v vladnih in drugih uradih v sosednjih deželah.

Med začetnimi darovi izrazito prevladujejo pravne in teološke vsebine, od konca 18. stoletja naprej pa skladno s splošnimi kulturno-znanstvenimi trendi tudi naravoslovne in uporabne vede. Po vsebinski homogenosti izstopajo predvsem večji sklopi, kot so teološka zbirka Karla Peera, medicinska zbirka Jakoba Pfandla, pravna zbirka Andreja Hohenwarta ter botanična zbirka Franca Hladnika. Tu sta še bogat sklop s področja zgodovinopisja, ki ga je prispeval Kranjski deželni muzej, ter jezikoslovna zbirka Frana Miklošiča, ki jo je knjižnica prejela leta 1848. Najbolj ažurne vsebine s področja naravoslovja in uporabnih ved je prispeval Žiga Zois. V vseh večjih podarjenih zbirkah so zastopani tudi pomembni avtorji in naslovi s področja klasične, srednjeveške ter zgodnje-novoveške znanosti, književnosti in jezikoslovja.

Do leta 1848 je bilo na ljubljanskem liceju mogoče študirati na treh smereh, in sicer filozofski (»splošni humanistični uvod « v kateri koli nadaljnji študij, ki je obsegal filozofijo, matematiko, grščino, praktično filozofijo, in verouk), mediko-kirurški ter teološki (omogočala je znanstveno izobraževanje teologov, pa tudi duhovnikov za praktično dušnopastirsko delo). ${ }^{65}$ Med neobveznimi predmeti so bili tudi tuji jeziki, na primer italijanščina in francoščina, ter poljedelstvo, zgodovina in filozofija. ${ }^{66}$ Pomembno vlogo pri oblikovanju nabavne politike in vsebine knjižnice je poleg omenjenih treh fakultet imela tudi gimnazija s svojim profesorskim in gimnazijskim zborom, ki je bila $\mathrm{v}$ isti stavbi kot licej in knjižnica. ${ }^{67}$ Donacije posameznikov iz najzgodnejšega obdobja kažejo relativno vsebinsko skladnost s kurikulumom liceja in gimnazije, predvsem na področju teologije, prava in klasičnih književnosti, nekoliko kasneje pa tudi na področju naravoslovja, zgodovinopisja in uporabnih ved. V veliko primerih je pri darovih šlo za knjige, ki jih profesorji

64 Stefan, Zgodovina C. kr. študijske knjižnice v Ljubljani, 50 in 68.

65 »Cesarsko-kraljevi licej« in Ciperle, Podoba velikega učilišča ljubljanskega, 163-230.

66 Ciperle, Podoba velikega učilišča ljubljanskega, 10.

67 Prav tam, 262. 
ali študenti iz različnih razlogov niso več potrebovali. Tako so se v knjižni zbirki nabirali tudi naslovi, ki niso bili vedno najbolj ažurni in aktualni. V zvezi s tem je zanimiva pripomba generalnega inšpektorja za javni pouk, ki je leta $1810 \mathrm{v}$ poročilu o stanju knjižnice zapisal, da je v zbirki veliko zastarelih, popolnoma odvečnih del, ki so jemala prostor boljšim delom, in bi jih bilo treba izločiti in prodati. ${ }^{68}$ Vendar omenjenih redundanc ne bi smeli pripisovati zgolj »zastarelim« donacijam. Šlo je namreč tudi za širši splet okoliščin, vključno s prostorsko oziroma postavitveno neurejenostjo celotne zbirke ter operativnimi problemi, povezanimi s hudimi zaostanki pri urejanju (s tem pa gotovo tudi pri selekciji) obstoječega fonda, ki so bili posledica nenadnih velikih prirastov (tudi neažurnih vsebin) v obdobju od ustanovitve knjižnice pa do začetka 19. stoletja, ${ }^{69}$ oziroma kadrovsko podhranjenostjo.

Po marčni revoluciji je v Ljubljani ostala samo teološka fakulteta kot edina oblika univerzitetnega študija. Leta 1952 se je iz licejske stavbe preselila v škofijsko semenišče. ${ }^{70} \mathrm{Z}$ razpustitvijo liceja leta 1850 je bila licejska knjižnica preoblikovana $\mathrm{v}$ javno Cesarsko-kraljevo študijsko knjižnico. Vsebine darov iz tega obdobja sicer postajajo vse bolj raznovrstne, v skladu s prevladujočimi kulturno-znanstvenimi trendi pa se med darovi povečuje predvsem delež slovanskega oziroma slovenskega jezikoslovja in književnosti ter tehničnih in uporabnih ved.

\section{SKLEP}

Ob pregledu obsega in vsebine darov ter splošnih okoliščin in profilov darovalcev, ki so svoje zbirke ali posamezne knjige podarili licejski oziroma študijski knjižnici, se nakazujejo osrednji vzgibi, ki se bistveno ne razlikujejo od motivov današnjih darovalcev. V prvih letih po letu 1774 prevladuje splošna mecensko-darovalska vnema, ${ }^{71} \mathrm{ki}$ je gotovo posledica stremljenja k čim obsežnejši študijski zbirki ob začetku delovanja liceja. Kasneje se temu pridruži še težnja $\mathrm{k}$ skladnosti darovanih vsebin s študijskimi programi in širšimi kulturno-znanstvenimi trendi. Vseskozi so prisotni tudi posamezni darovi protokolarne narave in donacije kot izraz pripadnosti matični izobraževalni ustanovi. Pri prvih gre za darove pomembnih političnih osebnosti oziroma plemstva, pri slednjih pa prednjačijo predvsem na liceju in v licejski (študijski) knjižnici zaposleni profesorji, nekdanji študenti in bibliotekarji. V vsebini podarjenih knjig se, tako kot pri rednih nakupih, zrcalijo tudi splošni trendi na področju razvoja znanosti in umetnosti v širših, pa tudi lokalnih okvirjih.

68 Stefan, Zgodovina C. kr. študijske knjižnice v Ljubljani, 34.

$69 \mathrm{~V}$ zvezi s tem glej tudi: Kodrič-Dačić, A. T. Linhart in ustanovitev prve javne znanstvene knjižnice na Kranjskem.

70 Ciperle, Podoba velikega učilišča ljubljanskega: Licej v Ljubljani 180o-1848, 249.

71 Zanimivo je, da je med najzgodnejšimi darovalci v različnih virih omenjen tudi Janez Jakob Schilling, ki je sicer umrl že leta 1754 in tako svojih knjig nikakor ni mogel darovati liceju oziroma licejski knjižnici. Stefan, Zgodovina C. kr. študijske knjižnice v Ljubljani, 28 in 33. 


\section{BIBLIOGRAFIJA}

Accessions-Protokolle der Studienbibliothek in Laibach. Angefangen 1835 beendet mit 1860 . Rokopisno gradivo, NUK.

Adam, Lucijan Stanislav. »Kranjski antifonar in grb mesta Kranja.« Linhartovi listi 7, 27 (2008): 1-6.

"Aufnahms-Bogen auf Jahre 1816." V: Zgodovina Slovenije-SIstory, www.sistory.si/ IGNORED_PUBLIC/popisi/1/Mesto\%20126_1.jpg (obiskano 4. 11. 2016).

Bibliothecae Caes. Reg. Lycei Labac. Catalogi Supplementum I. Rokopisno gradivo

Bucherverzeichniss aus dem Peerischen Verlass. Rokopisno gradivo, NUK Ms 1942.

"Cesarsko-kraljevi licej«, www.uni-lj.si/univerzitetni_arhiv/zgodovina_ul/.

Ciperle, Jože. Podoba velikega učilišča ljubljanskega: Licej v Ljubljani 180o-1848. Ljubljana: Slovenska matica, 2001.

Fenlon, John Francis. „Codex Amiatinus.« V: The Catholic Encyclopedia. Vol. 4. New York: Robert Appleton Company, 1908.

Glonar, Joža. »Knauer, Janez Jakob.« V: Slovenska biografija, www.slovenska-biografija. si/oseba/sbi278789/.

Gspan, Alfonz. »Taufferer, Inocenc, plemeniti.« V: Slovenska biografija, www.slovenskabiografija.si/oseba/sbi685034/ (uporabljeno 27. 9. 2016).

Kidrič, Francè. »Peer, Karel, plemeniti.« V: Slovenska biografija, www.slovenska-biografija.si/oseba/sbi409133/.

Kodrič-Dačić, Eva. "A. T. Linhart in ustanovitev prve javne znanstvene knjižnice na Kranjskem" V Anton Tomaž Linhart : jubilejna monografija ob 250-letnici rojstva, 351-377. Ljubljana: Slovenski gledališki muzej; Radovljica: Muzeji radovljiške občine, 2005).

Kodrič-Dačić, Eva. »Konrad Stefan in njegova zgodovina Cesarsko kraljeve Študijske knjižnice v Ljubljani.« V: Konrad Stefan, Zgodovina C. kr. študijske knjižnice v Ljubljani, 70-73. Ljubljana: Narodna in univerzitetna knjižnica; Zveza bibliotekarskih društev Slovenije, 2009.

Kranjc, Andrej. »Agapito, Girolamo.« V: Slovenska biografija, www.slovenska-biografija. si/oseba/sbi10oo15o/.

Labowsky, Loti. Bessarion's Library and the Biblioteca Marciana: Six Early Inventories. Rome: Edizioni di storia e letteratura, 1979.

Pintar, Ivan. »Hladnik, Franc de Paula.« V: Slovenska biografija, www.slovenska-biografija.si/oseba/sbi232152/.

Pintar, Ivan. »Pfandl, Jakob.« V: Slovenska biografija, www.slovenska-biografija.si/oseba/ sbi421884/.

Pivec-Stelè, Melita. »Wilde, Franz Xaver.« V: Slovenska biografija, www.slovenska-biografija.si/oseba/sbi840437/.

Prioreschi, Plinio. A History of Medicine: Volume III: Roman Medicine. Omaha: Horatius Press, 2001.

Rudolf, Andrejka. »Raigersfeld rodbina.« V: Slovenska biografija, www.slovenska-biografija.si/rodbina/sbi48137o/.

Smolik, Marijan. »Janez Krstnik Prešeren in prva javna znanstvena knjižnica v Ljubljani.« V: Academia operosorum: zbornik prispevkov s kolokvija ob 3oo-letnici ustanovitve, ur. Kajetan Gantar, 61-70. Ljubljana: Slovenska akademija znanosti in umetnosti, 1994.

Specification deren Büchern welche zum Theill in dem gewesten Collegio zu Laybach in 
einen Kasten verwahret gewesen, und zum Theill durch Studentes nach und nach zusammen getragen worden. $(1,1775)$. Rokopisno gradivo, NUK Ms 1940.

Stariha, Gorazd. »«Pri tem je odpel hlače in...« Ljubljanski mestni uradniki v prvi polovici prejšnjega stoletja.« Kronika 43, št. 1/2 (1995): 25-34.

Stefan, Konrad. Zgodovina C. kr. študijske knjižnice v Ljubljani. Ljubljana: Narodna in univerzitetna knjižnica; Zveza bibliotekarskih društev Slovenije, 2009.

Svoljšak, Sonja, in Urša Kocjan. Provenience starih tiskov Narodne in univerzitetne knjižnice. Ljubljana: Narodna in univerzitetna knjižnica, 2013.

Šter, Katarina. "Srednjeveški koral v kartuziji Žiče: pogled skozi oči najstarejšega samostanskega antifonarja: elektronska izdaja." V: Slovenska glasbena dediččina, 3, Ljubljana: Muzikološki inštitut ZRC SAZU, 2013.

Valenčič, Vlado, Ernest Faninger, in Nada Gspan-Prašelj. »Zois plemeniti Edelstein, Žiga.« V: Slovenska biografija, www.slovenska-biografija.si/oseba/sbi872726/.

Verzeichniss der Bucher, welche der gymnasial Prafekt Hr. Baron v. Taufferer in die lyzeal Bibliothek den 1s April 1791 uberliefert hat. Rokopisno gradivo, NUK Ms 1941.

Verzeichniss der Laybacher akademischen Büchersammlung kraft des gemachten Inventariums den 4ten May 1788. (1). Rokopisno gradivo, NUK Ms 1946.

Verzeichniss der schätzbaren litärerischen Werke, die der Hoch und Wohlgeborne freyherr Sigismund von Zois der diesortigen Lyceal-Bibliothek in den Jahren 1808 und 1815 als ein Geschenk verehret hat. Rokopisno gradivo, NUK Ms 1950.

Vidmar, Luka. "Prva javna znanstvena knjižnica na Slovenskem." V: Sedemdeset let Biblioteke Slovenske akademije znanosti in umetnosti, ur. Marija Fabjančič et al., 95-117. Ljubljana: Slovenska akademija znanosti in umetnosti, 2008.

Zbirka posameznih popisov donacij: Peer, Barbo-Waxenstein, Knauer, Wilde, Agapito, kanonikat v Flachenfeldu, cesarski dvor, Vest, Hoffman, Damian und Sorge, Krausler. Rokopisno gradivo, NUK. 